\title{
Genomic structure, polymorphism and expression analysis of growth hormone-releasing hormone and pituitary adenylate cyclase activating polypeptide genes in the half-smooth tongue sole (Cynoglossus semilaevis)
}

\author{
Q. Ma ${ }^{1,2}$, S.F. Liu', Z.M. Zhuang', L. Lin", ${ }^{1,2}$ Z.Z. Sun ${ }^{2}$, C.L. Liu ${ }^{2}$, \\ Y.Q. $\mathrm{Su}^{1}$ and Q.S. Tang ${ }^{2}$ \\ ${ }^{1}$ College of Oceanography and Environmental Science, \\ Xiamen University, Xiamen, China \\ ${ }^{2}$ Key Laboratory for Fishery Resources and Eco-Environment, \\ Yellow Sea Fisheries Research Institute, \\ Chinese Academy of Fishery Sciences, Qingdao, China
}

Corresponding author: S.F. Liu

E-mail: liusf@ysfri.ac.cn

Genet. Mol. Res. 10 (4): 3828-3846 (2011)

Received June 6, 2011

Accepted October 17, 2011

Published December 12, 2011

DOI http://dx.doi.org/10.4238/2011.December.12.1

\begin{abstract}
Growth hormone-releasing hormone (GHRH) and pituitary adenylate cyclase activating polypeptide (PACAP) regulate development and somatic growth in teleosts; they may be associated with sexual growth dimorphism in the half-smooth tongue sole (Cynoglossus semilaevis). We found that the full-length GHRH and PACAP gene sequences obtained from females and males consist of $4160,4159,2425$, and $2446 \mathrm{bp}$, respectively, each of which includes four exons and three introns. When we analyzed normal females and males and extra-large male adults, GHRH and PACAP mRNA were found to be predominantly expressed in the brain; the expression levels
\end{abstract}


were highest in normal males. The extra-large males exhibited the lowest mRNA levels of both GHRH and PACAP. Sex differences in GHRH and PACAP mRNA expression during development were also examined in a full-sib family; GHRH and PACAP mRNA were detected at all 27 times sampled from 10 to 410 days old. The GHRH expression levels in females were significantly higher than in males at most of the stages between 20 and 100 days old, while lower than those of males after 120 days old. Five microsatellite loci were identified in GHRH and PACAP genes. We used these five polymorphic markers to genotype 224 individuals, and no significant differences were found between females and males from the Bohai Sea, the Yellow Sea and hatchery samples.

Key words: GHRH; PACAP; Microsatellite polymorphism; mRNA expression; Half-smooth tongue sole

\section{INTRODUCTION}

Growth hormone $(\mathrm{GH})$ is an important regulator of development and somatic growth in vertebrates. Hypothalamic control of GH secretion in mammals has long been considered as a classic paradigm of the "dual control" system with growth hormone-releasing hormone $(\mathrm{GHRH})$ and somatotropin release-inhibiting factor (SRIF, or somatostatin) (Goldenberg and Barkan, 2007). However, teleosts exhibit a more complex multifactorial hypothalamic regulation of GH secretion than in mammalian vertebrates because of the unique organization of the hypothalamo-pituitary axis (Gahete et al., 2009). Consequently, a number of neuroendocrine regulation factors are involved in GH release of the pituitary gland, not only from GHRH to pituitary adenylate cyclase activating peptide (PACAP), but also SRIF, gonadotropin-releasing hormone $(\mathrm{GnRH})$ etc. To date, the importance of GHRH and PACAP genes has received a good deal of attention for their connection with growth traits through regulating GH secretion.

GHRH was initially isolated from human pancreatic tumors. In mammals, this neuropeptide is mainly expressed and released from the arcuate nucleus of the hypothalamus and plays a major role in causing the release of GH from somatotroph cells of the HypothalamicPituitary axis (Mayo et al., 1995). PACAP was first isolated from ovine hypothalamus extracts based on its ability to stimulate adenylate cyclase activity in rat pituitary cell cultures. Two biologically active forms of PACAP, a 38 amino acid form $\left(\mathrm{PACAP}_{38}\right)$ and a $27 \mathrm{~N}$-terminal amino acid form $\left(\mathrm{PACAP}_{27}\right.$ ) were identified, respectively. Evidence indicates that both forms of PACAP are derived from the same gene and mRNA precursor (Arimura and Shioda, 1995). In fish, PACAP is a pleiotropic hormone as an enhancer which potently stimulates the release of GH (Wong et al., 2000; Rousseau et al., 2001), gonadotropin (Wong et al., 2000), prolactin, adrenocorticotrophic hormone (ACTH) and luteinizing hormone (LH) (Fradinger and Sherwood, 2000). The PACAP mRNA precursor also encodes PACAP-related peptide (PRP), which also enhances the growth rates like PACAP as reported in fish (Lugo et al., 2008).

Based on their high homology in amino acid sequence with VIP, GHRH and PACAP both belong to the VIP-secretin-GHRH-glucagon superfamily. These two genes are encoded by two separate genes on separate chromosomes in mammals. Whereas in non mammalian vertebrates and protochordates, it was originally hypothesized that GHRH gene was encoded in 
the same with PACAP gene (McRory and Sherwood, 1997). Consistent results have also been reported in fish, such as catfish (Ictalurus punctatus) (McRory et al., 1995), zebrafish (Danio rerio) (Fradinger and Sherwood, 2000) and salmon (Parker et al., 1997). Recent research has indicated that GHRH-like peptides were homologues of mammalian PACAP-related peptides, whereas, genes encoding only GHRH peptides were identified in goldfish (Carassius auratus), zebrafish (D. rerio), and African clawed frog (Xenopus tropicalis) (Lee et al., 2007). Moreover, the cDNAs encoding PRP/PACAP and GHRH in half-smooth tongue sole were also cloned, respectively (Ji et al., 2011). However, data on the structure of the GHRH and PACAP genes in teleosts have been rarely reported in the literature.

Sexually dimorphic growth exists in many teleosts. In certain fish species, such as tilapia, males grow faster and larger than females, while in Chinook salmon (Oncorhynchus tshawytscha), Common carp (Cyprinus carpio), Atlantic halibut and half-smooth tongue sole (Cynoglossus semilaevis), females grow significantly faster and larger than males. The halfsmooth tongue sole is an increasingly important marine flatfish of potentially great aquacultural value in China (Liu et al., 2005). This species exhibits a typical sexual dimorphism in which females grow 2 to 3 times faster and larger than males. In the natural setting, the full length of the mature females is twice as large and the weight over six times greater than mature males. The physiologic mechanism of this sexual growth dimorphism in half-smooth tongue sole is of great interest and remains to be clarified. Owing to the important functions of GHRH and PACAP in regulating GH and further influence growth, determining the relative GHRH and PACAP gene expressions between females and males during the different contrasting developmental stages may help elucidate their roles in the sex-associated dimorphic growth of half-smooth tongue sole. However, the expression pattern of the growth-related genes associated with fish sexual dimorphism has thus far only rarely been reported (Degani et al., 2003; Ji et al., 2011).

In order to gain a better understanding of this sex-associated dimorphic growth phenomenon, we characterized the GHRH and PACAP genes by using homology cloning and chromosome walking methods, and investigated the polymorphisms in these two genes to determine whether microsatellite polymorphisms are associated with the sex related growth of half-smooth tongue sole. Additionally, sex specific tissue expression of GHRH and PACAP among females, males and extra-large males were examined by using real-time quantitative PCR, and their mRNA expression levels between the sexes at different developmental stages from a full-sib family were determined to gain insight into the mechanisms of sexual growth dimorphism.

\section{MATERIAL AND METHODS}

\section{Experiment design and sample source}

The experiment was designed to examine the differences of genomic structure, mRNA expression and microsatellite polymorphisms in GHRH and PACAP genes between the female and male half-smooth tongue sole at both the individual and population levels.

Mature female and male individuals of the same age were used to detect the GHRH and PACAP mRNA tissue expression distribution patterns. In addition, two extra-large male individuals which are rarely observed in the aquaculture populations were used to compare the GHRH and PACAP mRNA expression levels with normal female and male fish. The information on the above-mentioned fish samples is shown in Table 1. After being rapidly dissected 
from the above-mentioned 14 live individuals, 14 tissues (blood, brain, gill, gonad, heart, intestine, kidney, liver, muscle, pituitary, spinal cord, skin, spleen, and stomach) were immediately frozen in liquid nitrogen, and kept at $-80^{\circ} \mathrm{C}$ until use.

Table 1. Mature half-smooth tongue sole samples.
\begin{tabular}{lccccc}
\hline Samples & $\begin{array}{c}\text { Numbers of } \\
\text { individuals }\end{array}$ & $\begin{array}{c}\text { Age } \\
\text { (years) }\end{array}$ & $\begin{array}{c}\text { Mean body } \\
\text { length }(\mathrm{mm})\end{array}$ & $\begin{array}{c}\text { Mean body } \\
\text { weight }(\mathrm{g})\end{array}$ & Sample source \\
\hline Female & 6 & 3 & $583.00 \pm 61.25$ & $1479.17 \pm 280.80$ & $\begin{array}{l}\text { Mingbo Hatchery Station } \\
\text { (Laizhou, Shandong Province) }\end{array}$ \\
$\begin{array}{l}\text { Male } \\
\text { Extra-large male }\end{array}$ & 6 & 3 & $333.33 \pm 14.30$ & $170.33 \pm 16.86$ & $\begin{array}{l}\text { Xinyongfeng Hatchery Station } \\
\text { (Tianjin, China) }\end{array}$ \\
\hline
\end{tabular}

To minimize factors influencing gene expression, such as genetic background, as well as ontogenetic and environmental influences, a full-sib family of the half-smooth tongue sole was constructed and grown to supply samples used in examining the difference in the ontogenetic expression pattern in GHRH and PACAP mRNA among siblings at the different developmental stages. Using a pair of wild parent fish caught in the Yellow Sea, a full-sib family was constructed in October 2008 at the Zhonghai Hatchery (Qingdao, Shandong Province) and grown in the same indoor concrete tank. Four to six individuals at each developmental stage (interval of 10 days between 10 to 150 days-old, interval of 20 days between 150 to 350 days-old, 380 and 410 days-old) were randomly collected from the full-sib family. As a result, a total of 138 fish were sampled under the condition of an empty stomach in the early morning. After determining the body length and weight, all the samples were frozen in liquid nitrogen for RNA and DNA extraction.

A total of 131 wild individuals, 70 and 61 of which were respectively collected from the Bohai Sea (BS) and the Yellow Sea (YS) in 2007, together with 93 individuals from the above-mentioned full-sib family (HS), were used to detect microsatellite polymorphisms of the GHRH and PACAP genes between the female and male half-smooth tongue sole at the population level. The muscle tissues were dissected from these 224 individuals and preserved in ethanol at $-20^{\circ} \mathrm{C}$ for DNA isolation.

\section{DNA isolation and cDNA synthesis}

Genomic DNA was extracted using standard phenol-chloroform extraction procedures (Sambrook et al., 1989) from the brain and muscle tissues. The quality and concentration of DNA were assessed by agarose gel electrophoresis and measured with NanoVue ${ }^{\mathrm{TM}}$ (GE Healthcare). Finally, DNA was diluted to $100 \mathrm{ng} / \mu \mathrm{L}$ and stored at $-20^{\circ} \mathrm{C}$ for future use.

Total RNA was extracted from frozen tissues of adult fish and samples of different developmental stages using TRIzol Reagent (Invitrogen, USA) according to manufacture instructions. The isolated RNA samples were suspended in DEPC-treated water and quantified using NanoVue ${ }^{\mathrm{TM}}$ (GE Healthcare) at $\mathrm{A}_{260} \mathrm{~nm}$ and $\mathrm{A}_{280} \mathrm{~nm}$, and then analyzed for its integrity on agarose gel. The first-strand cDNA was synthesized from total RNA using Reverse Transcriptase M-MLV (Takara Bio Inc., China) following manufacturer instructions. 


\section{Genetic sex identification}

Genetic sex identification was determined using the female-specific SCAR marker developed by Chen et al. (2007), with a pair of female-specific PCR primers (CseF382N1 and CseF382C1). A female-specific fragment of $350 \mathrm{bp}$ was amplified from the genotypic female individuals. The results were further verified by another sex-specific marker which amplifies particular fragments from differently sexed individuals (Wang XB et al., unpublished results).

\section{cDNA isolating and gene cloning}

According to the full-length cDNA sequences of GHRH and PACAP genes, two pairs of degenerate primers, GHRH-GENE-F/R and PACAP-GENE-F/R (Table 2), were designed to amplify the genomic sequence of the GHRH and PACAP genes using genomic DNA of half-smooth tongue sole as the template. The sequences were amplified using the LA Taq kit (Takara Bio., China) and the PCR reactions were performed following manufacturer instructions. PCR amplification was conducted under the following conditions: an initial denaturing at $94^{\circ} \mathrm{C}$ for $1 \mathrm{~min}$, followed by 30 cycles of $98^{\circ} \mathrm{C}$ for $10 \mathrm{~s}$ and $68^{\circ} \mathrm{C}$ for $3 \mathrm{~min}$, with a final extension at $72^{\circ} \mathrm{C}$ for $10 \mathrm{~min}$.

\begin{tabular}{|c|c|c|}
\hline Name & Primer sequences (5' to $\left.3^{\prime}\right)$ & Amplification target \\
\hline GHRH-GENE-F & 5'-GCAGTTGTCCACTCCTGTC-3' & DNA fragment of GHRH \\
\hline GHRH-GENE-R & 5'-TCCAATCATGCTCCTCCC-3' & \\
\hline GHRH-GE-SP1 & 5'-CTAAAGGTTTCTTGGTTTCCATTCT-3' & DNA fragment of GHRH \\
\hline GHRH-GE-SP2 & 5'-ACAGTGACGAGGAGAAGAAGAACAG-3' & \\
\hline GHRH-GE-SP3 & 5'-ATGACCAGGCAACAACAGAGCA-3' & \\
\hline PACAP-GENE-F & 5'-ATGGCCAGTTCGAGTAAAGCCAC-3' & DNA fragment of PACAP \\
\hline PACAP-GENE-R & 5'-CTACAAATAGGCAAGCCGGCGTCC-3' & \\
\hline GHRH-SSR-F1 & 5'-TGTATGCCTAATTATCCTAAT-3' & SSR of GHRH \\
\hline GHRH-SSR-R1 & 5'-GTCGTAACTGATGTCTTTTTC-3' & \\
\hline GHRH-SSR-F2 & 5'-AGTAAATAGTTCACAGGCATAA-3' & SSR of GHRH \\
\hline GHRH-SSR-R2 & 5'-TAGTCACTCCCACATCACAT-3' & \\
\hline GHRH-SSR-F3 & 5'-ССТТСТААТССТСТСТАТТТССС-3' & SSR of GHRH \\
\hline GHRH-SSR-R3 & 5'-AAGACAGAGTGATGAAGACAACC-3' & \\
\hline GHRH-SSR-F4 & 5'-TTTCATAACCTTCACAAATCA-3' & SSR of GHRH \\
\hline GHRH-SSR-R4 & 5'-AATGTCACTCTGGTACAGCAC-3' & \\
\hline PACAP-SSR-F & 5'-ATGACAGTTCGTGCAGGGTA-3' & SSR of PACAP \\
\hline PACAP-SSR-R & 5'-TCACGCCACCAAACAACA-3' & \\
\hline GHRH-RT-F & 5'-CTGAGGGACGATATGAGTCTTG-3' & Expression of GHRH \\
\hline GHRH-RT-R & 5'-GAACTTCCTGGCTGAAATCTG-3' & \\
\hline PACAP-RT-F & 5'-GCATCTTCACCGACAGCTACA-3' & Expression of PACAP \\
\hline PACAP-RT-R & 5'-GGCGTCCTTTGTTCCTTACTCT-3' & \\
\hline$\beta$-actin- $F$ & 5'-GTAGGTGATGAAGCCCAGAGCA-3' & Expression of $\beta$-actin mRNA \\
\hline$\beta$-actin-R & 5'-CTGGGTCATCTTCTCCCTGT-3' & \\
\hline CseF382N1 & 5'-ATTCACTGACCCCTGAGAGC-3' & Genetic sex identification[23] \\
\hline CseF382C1 & 5'-AACAACTCACACACGACAAATG-3' & \\
\hline
\end{tabular}

The chromosome walking method was used to isolate the complete GHRH genomic sequence. Three gene-specific primers, GHRH-GE-SP1, GHRH-GE-SP2 and GHRH-GE-SP3 were designed for the amplification of the first exon and the promoter region. The sequences were amplified using the Genome Walking Kit (Takara Bio., China) and the PCR reactions were performed following manufacturer instructions. 
All the amplified fragments of the expected sizes were purified with a Tiangen gel extraction kit (Tiangen, China) and cloned into pMD18-T vector (Takara Bio., China), then transformed into Escherichia coli DH5 $\alpha$ and sequenced by the Huada Gene Company (Beijing, China).

\section{Sequence analysis}

The full length gene sequences were assembled by aligning the overlapping fragments and the primer sequences. The DNA and deduced amino acid sequences were analyzed using EditSeq and DNAMAN softwares. An mRNA-to-genomic alignment program (http://www.ncbi.nlm.nih. gov/spidey/) was employed to determine the organization of GHRH and PACAP genes. The promoter region analysis was performed using Promoter Scan (http://www-bimas.cit.nih.gov/molbio/ proscan/) and TFSEARCH program (http://pdap1.trc.rwcp.or.jp/research/db/TFSEARCH.html).

\section{Quantitative real-time PCR}

Quantitative real time PCR (qRT-PCR) of the GHRH and PACAP genes was conducted to determine whether the differentially expressed genes had a sex-specific expression pattern in terms of tissue distribution or the different developmental stages. The tissues collected from mature females and males were pooled respectively to generate sufficient amounts of the three cDNAs for tissue distribution analysis. To examine the change and possible sex differences in GHRH and PACAP mRNA expression during development, the cDNAs from the same stage of the same sex were also pooled to form single sex sample pools for expression analysis.

The primers GHRH-RT-F, GHRH-RT-R, PACAP-RT-F and PACAP-RT-R were used for amplifying the GHRH and PACAP fragments, respectively (Table 2). qRT-PCR was conducted on a 7500 ABI Real time PCR system (Applied Biosystems, USA). Amplifications were performed in a $20 \mu \mathrm{L}$ final volume containing $1 \mu \mathrm{L}$ cDNA sample, $10 \mu \mathrm{L}$ SYBR ${ }^{\circledR}$ Premix Ex Taq ${ }^{\mathrm{TM}}$ (Perfect Real Time) (Takara Bio., China), $0.4 \mu \mathrm{L}$ ROXII, $0.4 \mu \mathrm{L}$ of each primer and $7.8 \mu \mathrm{L} \mathrm{ddH_{2 }}$ O. A negative control was always included. PCR amplifications were performed in triplicate, using the following conditions: initial denaturing at $95^{\circ} \mathrm{C}$ for $10 \mathrm{~s}$, followed by 40 cycles of $5 \mathrm{~s}$ at $95^{\circ} \mathrm{C}$ and $34 \mathrm{~s}$ at $60^{\circ} \mathrm{C}$. A dissociation protocol was performed after thermocycling to determine target specificity. Expression of $\beta$-actin was used as the internal control for GHRH and PACAP gene expression analysis. The ratio change in the target gene relative to the $\beta$-actin control gene was determined by the $2^{-\Delta \Delta \mathrm{Ct}}$ method (Livak and Schmittgen, 2001) and the transcript level was described in terms of its relative concentration $\left(\mathrm{RC}_{\text {gene }} / \mathrm{RC}_{\beta \text {-actin }}\right)$.

\section{GHRH and PACAP microsatellite polymorphism analysis}

Four microsatellite sequences, $(\mathrm{AT})_{5},(\mathrm{AG})_{12},(\mathrm{TC})_{5}$ and $(\mathrm{GA})_{7}$, were found in the GHRH gene of half-smooth tongue sole, which were defined as GHRH-SSR1, GHRH-SSR2, GHRH-SSR3 and GHSSR4, respectively. A microsatellite sequence, (ATT), was found in the PACAP gene and defined as PACAP-SSR. On the basis of the sequence information of GHRH and PACAP genes, a total of five pairs of primers (Table 2) were designed which were complementary to the flanking regions for PCR amplification of the microsatellites.

Amplification of each DNA sample was performed in a typical reaction mixture. The cycle conditions were one initial denaturing stage for $5 \mathrm{~min}$ at $94^{\circ} \mathrm{C}$, then 35 cycles of $45 \mathrm{~s}$ at 
$94^{\circ} \mathrm{C}, 45 \mathrm{~s}$ at $55^{\circ} \mathrm{C}, 45 \mathrm{~s}$ at $72^{\circ} \mathrm{C}$ and a final extension stage for $10 \mathrm{~min}$ at $72^{\circ} \mathrm{C}$. Labeled PCR products were analyzed on an ABI PRISM ${ }^{\circledR} 3130$ Genetic Analyzer (Applied Biosystems, USA) with allele sizes estimated using a GeneScan-500 LIZ size standard (Applied Biosystems, USA) and the GeneMapper ${ }^{\circledR}$ version 3.7 software (Applied Biosystems, USA).

Genepop software 4.0 (Rousset, 2008) was used to calculate observed and expected heterozygosities and to test for Hardy-Weinberg proportions and linkage disequilibrium between pairs of loci, and also to test the differences between female and male half-smooth tongue sole (exact $\mathrm{G}$ test). The sequential Bonferroni method was applied to correct P-values using multiple comparisons (Rice, 1989). ARLEQUIN 3.5 (Excoffier and Lischer, 2010) was used to calculate pairwise $F_{\mathrm{ST}}$ for the analysis of population structure (Weir and Cockerham, 1984).

\section{Statistical analysis}

All data are reported as means \pm SD and were analyzed by one-way ANOVA (analysis of variance) to determine significant differences between samples using SPSS 16.0. Associations between body length, body weight and mRNA expressions of both genes were examined by spearman tests using SPSS 16.0. Values were considered to be statistically significant when $\mathrm{P}<0.05$.

\section{RESULTS}

\section{Growth characteristics of sample resources}

The ontogenetic growth of the full-sib family was recorded in increments of body length and weight related to age in days. As shown in Figure 1, body length was significantly associated with body weight in both the females and males within the period of 10 to 410 days-old $(\mathrm{P}<0.01)$. A slow growth stage from 20 to 40 days-old was observed $(\mathrm{P}>0.05)$, which may be related to metamorphosis. Little difference in body length or weight between the females and males were observed until 250d. However, the body length and weight of the mature female and male adults were significantly different. The body length and weight of extra-large male adults were obviously closer to those of female adults and significantly different from those of the normal male adults.

\section{The structure of the GHRH and PACAP genes}

The GHRH genomic sequences obtained from the female and male half-smooth tongue sole were $4160 \mathrm{bp}$ and $4159 \mathrm{bp}$, respectively. Four exons and three intervening introns were found in the GHRH genes of both the female and male (Figure 2). The corresponding exons in female and male fish have the same size of 125, 105, 105, and $142 \mathrm{bp}$, and the introns have the same size of 1900, 638 and $437 \mathrm{bp}$. The peptide cleavage site (R and GKR) is also determined in the third exon. In the promoter region of GHRH gene, a consensus TATA region is not detected, but a TATA-like element is observed at -594 to -602 bp upstream from the start codon. A GATA binding proteins 1 (GATA -1) consensus sequence is located at -624 to $-637 \mathrm{bp}$. Moreover, four cAMP response elements binding protein and two hepatocyte nuclear factor- $3 \beta$ elements (HNF$3 \beta$ ) consensus sequences are present in the promoter region of the GHRH gene (Figure 2). 


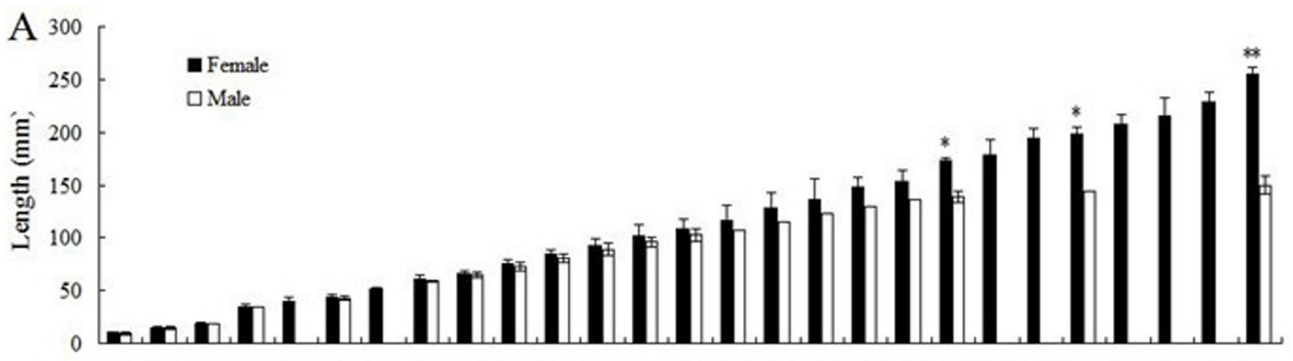

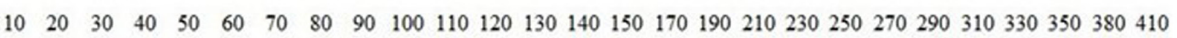

Age in days

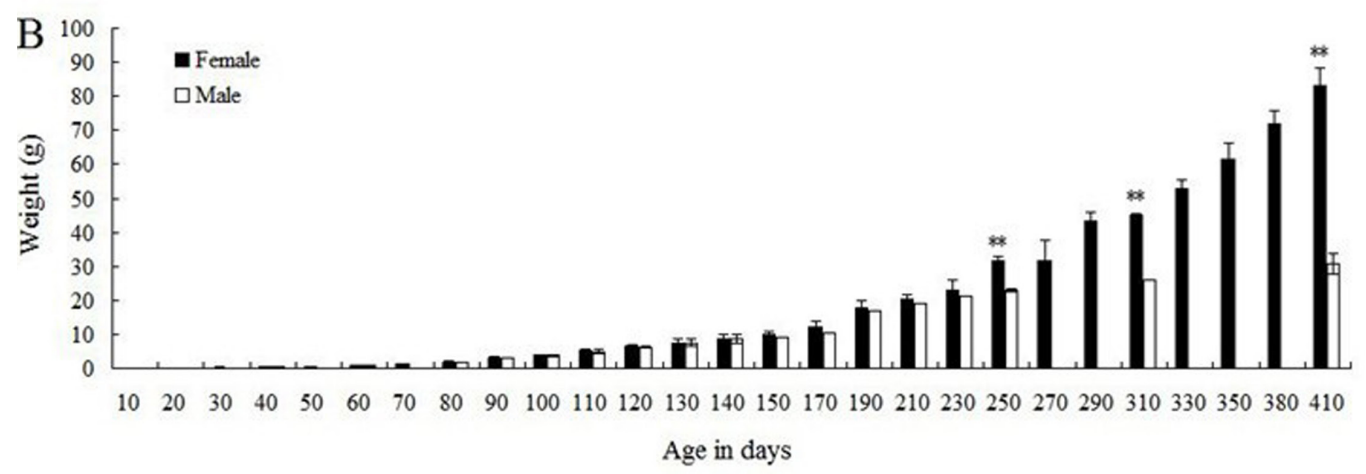

Figure 1. Comparison of the body length $(\mathbf{A})$ and body weight $(\mathbf{B})$ between female and male half-smooth tongue sole at different developmental stages. Data are reported as means \pm SE. Significant differences in body length and weight between the females and males are indicated with an asterisk at $\mathrm{P}<0.05$, and two asterisks at $\mathrm{P}<0.01$.

The PACAP genomic sequences obtained from the female and male half-smooth tongue sole were 2425 and $2446 \mathrm{bp}$, respectively, which consist of four exons and three introns and encode a protein of 175 AA (Figure 3). The corresponding exons in female and male fish have the same size of 104, 135, 105, and $184 \mathrm{bp}$, but the introns are of different size in the two sexes. The introns of the female PACAP gene are 934, 359 and $604 \mathrm{bp}$, while for the male PACAP gene they are 946, 360 and 612 bp (Figure 3). The sequence of PRP is encoded by the third and forth exons, and PACAP is encoded by the fourth exon.

There was no significant difference in the genetic organization of the GHRH and PACAP genes between the sexes. All the introns of both genes follow the consensus rule, i.e., starting with a GT dinucleotide and ending with an AG (Breathnach and Chambon, 1981).

\section{Expression analysis of GHRH and PACAP mRNA}

As determined by qRT-PCR, the tissue distribution of GHRH and PACAP mRNA in both female and male adults were detected. A high level of GHRH mRNA was detected in brain, and less expressed in pituitary and spinal cord (Figure 4). Also, GHRH mRNA can be detected in other tissues such as gonad, gill and blood. Moreover, there was no significant 


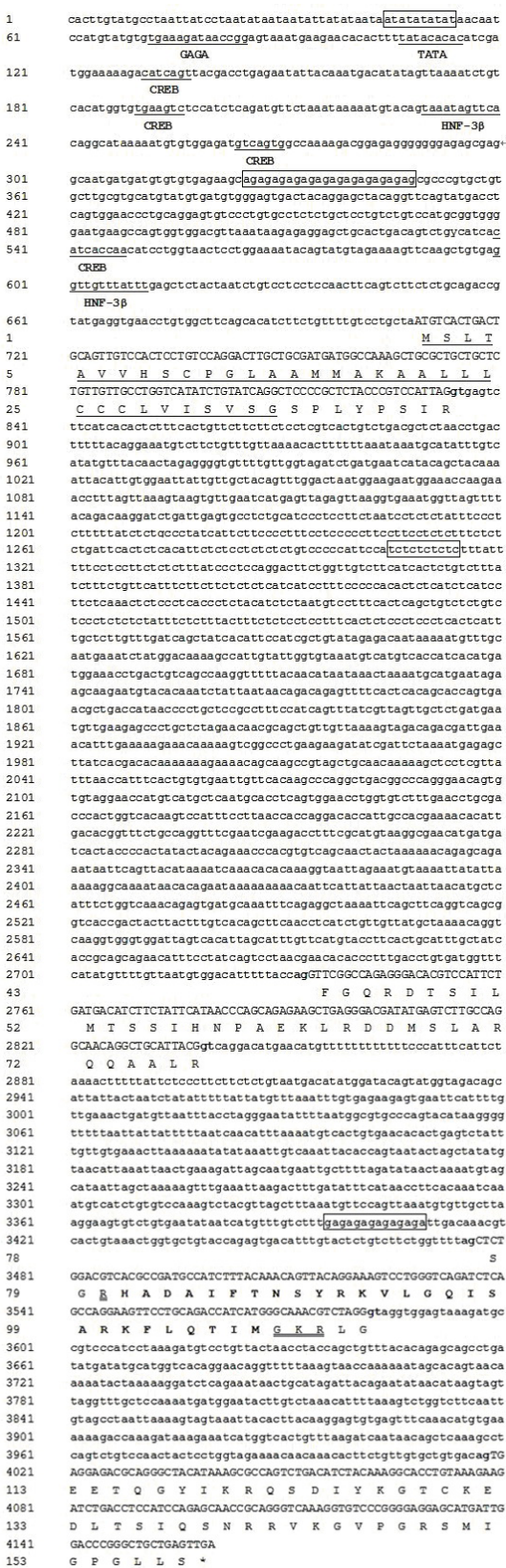

Figure 2. The structure of the half-smooth tongue sole GHRH gene and the deduced amino acid sequence. The deduced amino acid residues are represented as single letter abbreviations and numbered from the initiating methionine. The signal peptide is underlined, the mature peptide and the intron splicing consensus (gt/ag) are in bold and italicized letters. The stop codon is marked by an asterisk. The exons are in capital letters, while the introns and flanking regions are in lowercase letters. The microsatellite sites are boxed. Consensus sequences of the TATA box, GAGA-1 and HNF-3 $\beta$ are underlined in the $5^{\prime}$ flanking region, and the putative cleavage sites (R and GKR)

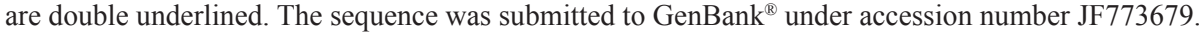




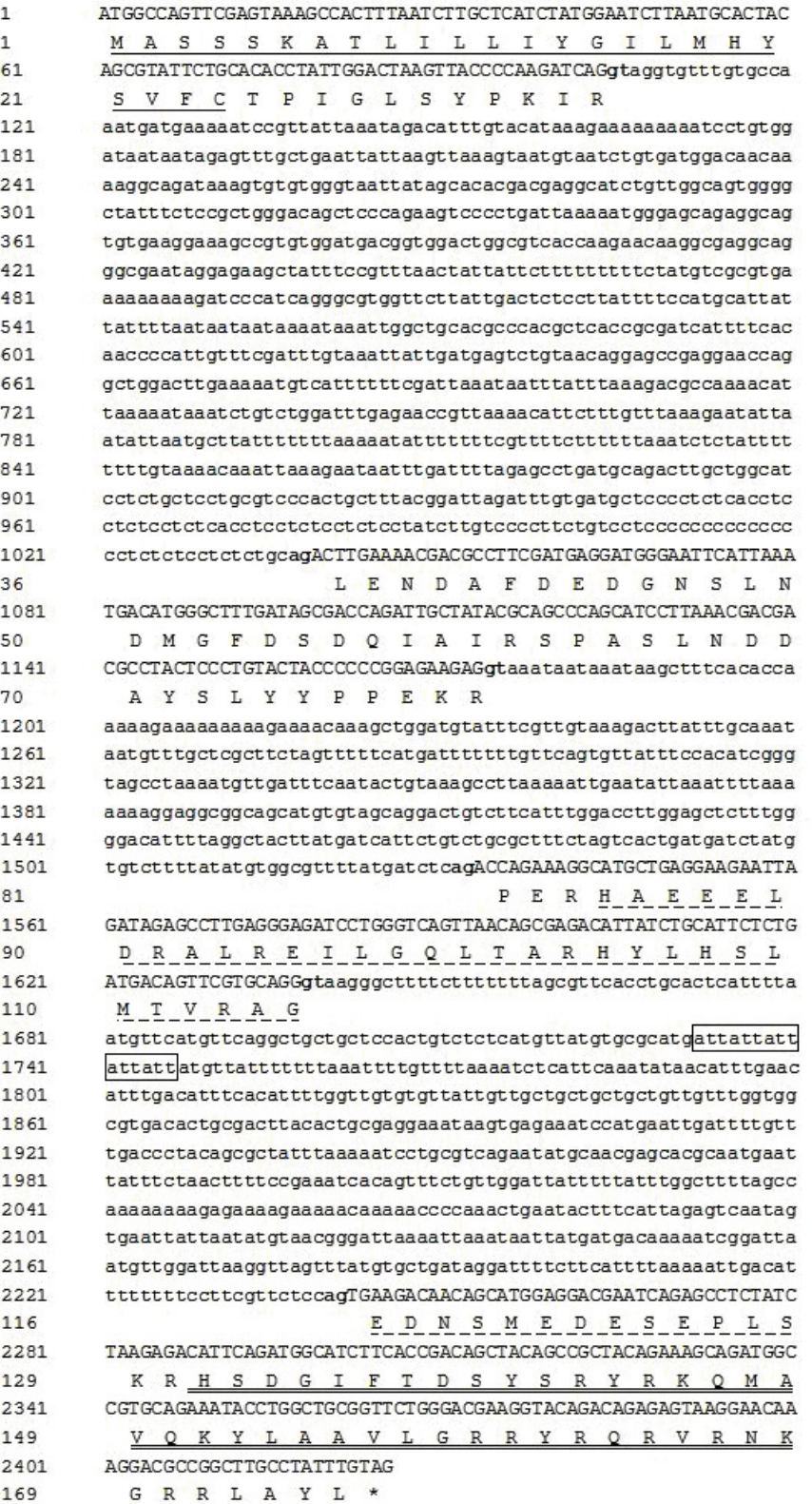

Figure 3. The structure of the half-smooth tongue sole PRP/PACAP gene and the deduced amino acid sequence. The deduced amino acid residues are represented as single letter abbreviations and numbered from the initiating methionine. The signal peptide is underlined, the mature peptide for PRP is dash underlined, and the mature peptide for PACAP is double underlined. The intron splicing consensus (gt/ag) are in bold and italicized letters. The stop codon is marked by an asterisk. The exons are in capital letters, the introns and flanking regions are in lowercase letters. The microsatellite sites are boxed. The sequence was submitted to GenBank $^{\circledR}$ under accession number HQ334202. 


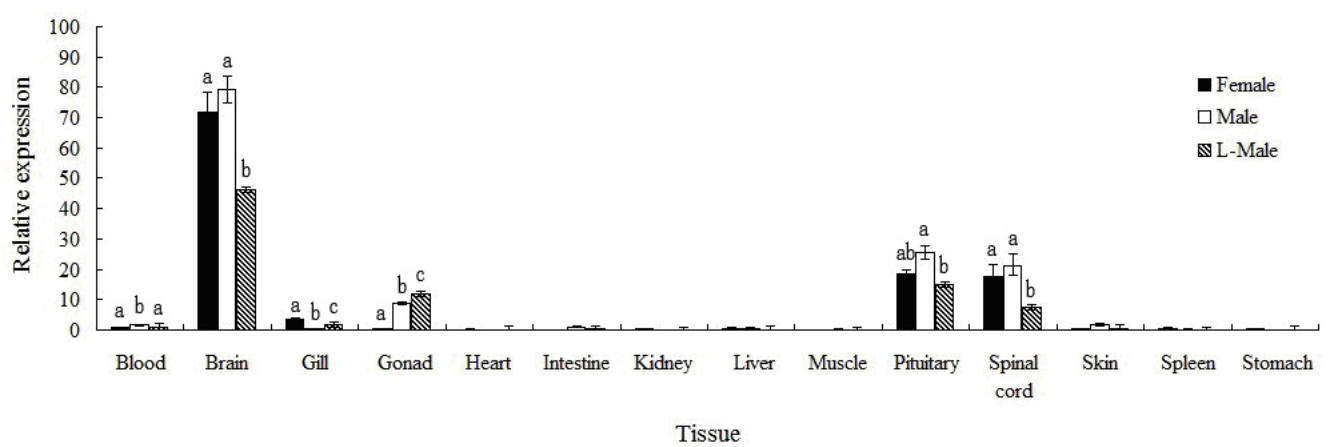

Figure 4. Expression of GHRH mRNA in various half-smooth tongue sole tissues. The GHRH expression levels are expressed as a ratio relative to the $\beta$-actin mRNA levels in the same samples. A relative abundance of 1 was set arbitrarily for the level in the blood of the females. Values are reported as means $+\mathrm{SD}(\mathrm{N}=3)$. The letters indicate significant differences $(\mathrm{P}<0.05)$. L-Male represents the extra-large male fish.

difference between females and normal males GHRH mRNA expression in brain, pituitary and spinal cord, while the mRNA expression of extra-large males was significant lower than that of females and normal males $(\mathrm{P}<0.01)$. Furthermore, GHRH mRNA expression of normal males was 1.1 times as high as those of females, and 1.7 times as much as those of extra-large males.

PACAP mRNA was predominantly detected in brain, and less expressed in spinal cord, skin and blood (Figure 5). Moreover, PACAP mRNA expression in the brain of males was 1.2 times as much as those of females $(\mathrm{P}<0.01)$, and 1.3 times as high as those of extralarge males $(\mathrm{P}<0.01)$.

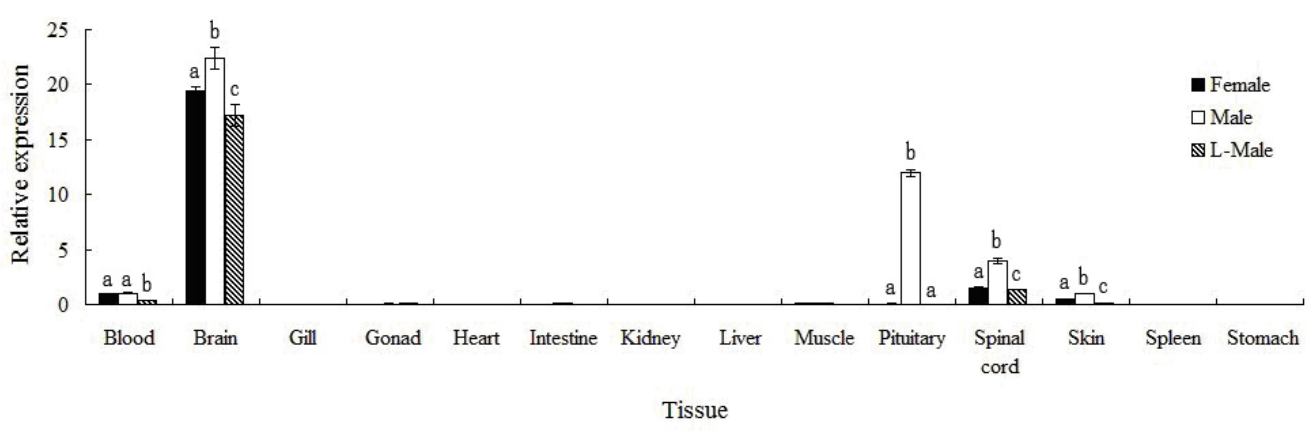

Figure 5. Expression of PACAP mRNA in various half-smooth tongue sole tissues. The PACAP expression levels are expressed as a ratio relative to the $\beta$-actin mRNA levels in the same samples. A relative abundance of 1 was set arbitrarily for the level in the blood of the females. Values are reported as means $+\mathrm{SD}(\mathrm{N}=3)$. Different letters indicated significant differences $(\mathrm{P}<0.05)$. L-Male represents fast growing male fish.

It is of great interest that the extra-large males exhibit the lowest mRNA levels of both GHRH and PACAP genes in the predominantly expressed tissues comparing with normal females and males. Furthermore, a significant high level of PACAP mRNA was only detected 
in pituitary gland of normal males, while in females and extra-large males the PACAP mRNA were at a negligible level in comparison with the significantly high level in normal males.

The GHRH mRNA expression at various stages exhibited a significant difference between the female and male groups, and the expression level in females was significantly higher $(\mathrm{P}<0.01)$ than that of males at most stages of the sampling period between 20 and 100 days-old, while the expression level in males was significantly higher $(\mathrm{P}<0.01)$ than that of females at most stages of the sampling period after 120 days-old (Figure 6). GHRH expression pattern differences between the sexes at 50d, 70d, 270d, 290d, 330d, 350d and 380d could not be conducted due to the absence of male samples. Correlation analysis demonstrated that GHRH mRNA expression was associated with body length $(\mathrm{P}=0.023)$ and body weight $(\mathrm{P}=$ $0.023)$ in males during the whole sampling period, while in females the expression level was associated with body length $(\mathrm{P}=0.039)$ and body weight $(\mathrm{P}=0.047)$ during the whole sampling period except for 410 days-old. GHRH mRNA expression in females was significantly lower than that of males at $10 \mathrm{~d}$ in this study, suggesting that the mRNA expression pattern differences were mainly caused by individual rather than sexual differences, because no difference in growth was observed at this stage.

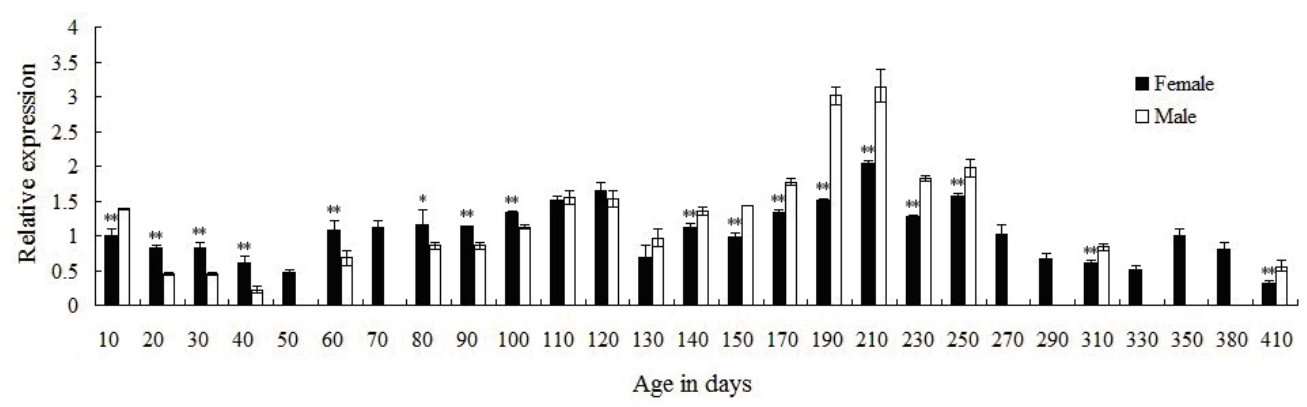

Figure 6. The quantitative RT-PCR analysis of GHRH mRNA expression level in female and male half-smooth tongue sole at various growth stages. d: days. GHRH expression levels were expressed as a ratio relative to the $\beta$-actin mRNA levels in the same samples. A relative abundance of 1 was set arbitrarily for $10 \mathrm{~d}$ in the females. All data are reported as means $+\mathrm{SD}(\mathrm{N}=3)$. Significant differences in the mRNA expression level between females and males are indicated with an asterisk at $\mathrm{P}<0.05$, and two asterisks at $\mathrm{P}<0.01$.

PACAP expression level of males was significantly higher $(\mathrm{P}<0.01)$ than that of females at most stages of the sampling period (Figure 7). Correlation analysis demonstrated that PACAP mRNA expression was associated with body length $(\mathrm{P}=0.000)$ and body weight $(\mathrm{P}=$ 0.000 ) in females during the growing period from $10 \mathrm{~d}$ to $410 \mathrm{~d}$, while in females the expression level was associated with body length $(\mathrm{P}=0.047)$ and body weight $(\mathrm{P}=0.047)$.

\section{GHRH and PACAP microsatellite markers and their polymorphisms}

Four microsatellite loci, GHRH-SSR1, GHRH-SSR2, GHRH-SSR3 and GHSSR4, were found in GHRH gene of half-smooth tongue sole, which were located in promoter region, intron 1 and intron 2, respectively. Moreover, another microsatellite locus, PACAP-SSR, was found in intron 3 of PACAP gene. These five loci were used to evaluate the genetic di- 


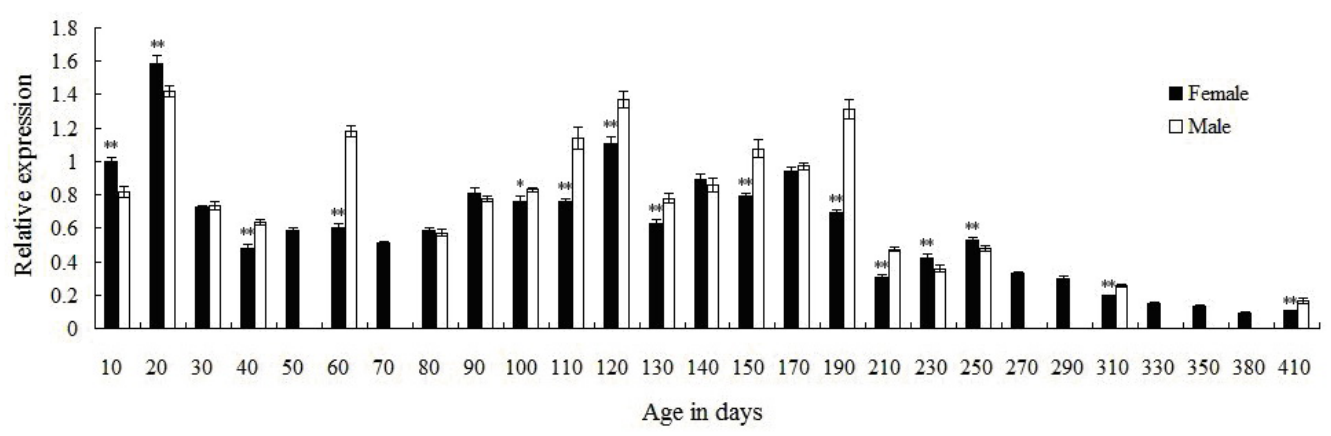

Figure 7. The quantitative RT-PCR analysis of PACAP mRNA expression level in female and male half-smooth tongue sole at various growth stages. d: days. PACAP expression levels are expressed as a ratio relative to the $\beta$-actin mRNA levels in the same samples. A relative abundance of 1 was set arbitrarily for $10 \mathrm{~d}$ in the females. All data are reported as means $+\mathrm{SD}(\mathrm{N}=3)$. Significant differences in the mRNA expression level between females and males were indicated with an asterisk at $\mathrm{P}<0.05$, and two asterisks at $\mathrm{P}<0.01$.

versity of the wild (the Bohai Sea and the Yellow Sea samples) and the hatchery sample. The results revealed that no genetic polymorphism was detected in any of the three samples at GHRH-SSR1, GHRH-SSR3 and GHSSR4. As indicated in Table 3, the number of alleles per locus ranged from 3 to 9 , with an average of 5.33. The observed and expected heterozygosities of both loci (GHRH-SSR2 and PACAP-SSR) ranged from 0.4286 to 0.7500 and from 0.5282 to 0.6749 , with an average of 0.5729 and 0.6107 , respectively. The HS sample displayed the smallest number of alleles, observed/expected heterozygosities, and polymorphism information content at both loci. Both loci showed significant deviation from Hardy-Weinberg proportions in the HS sample. The results of the pairwise $F_{\mathrm{ST}}$ calculation showed that there was no significant difference between the wild samples $\left(F_{\mathrm{ST}}=-0.0064, \mathrm{P}=0.8018\right)$, while significant differences were observed between the HS and BS samples $\left(F_{\mathrm{ST}}=0.1425, \mathrm{P}=0.0000\right)$, and also the HS and YS samples $\left(F_{\mathrm{ST}}=0.1634, \mathrm{P}=0.0000\right)($ Table 4$)$.

Table 3. Statistical analysis of the genetic variation in half-smooth tongue sole (C. semilaevis) by two microsatellite loci in the GHRH and PACAP genes.

\begin{tabular}{lcccccccl}
\hline Locus & Repeat motif & Sample & $\mathrm{N}$ & $N_{\mathrm{A}}$ & $H_{\mathrm{O}}$ & $H_{\mathrm{E}}$ & PIC & P \\
\hline GHRH-SSR2 & $(\mathrm{AG})_{12}$ & BS & 70 & 9 & 0.7500 & 0.6749 & 0.6096 & 0.2192 \\
& & YS & 61 & 7 & 0.6471 & 0.6628 & 0.6028 & 0.7235 \\
& & HS & 93 & 4 & 0.4286 & 0.6193 & 0.5479 & $0.0000^{*}$ \\
PACAP-SSR & $(\mathrm{ATT})_{6}$ & BS & 70 & 5 & 0.6557 & 0.6037 & 0.5202 & 0.0357 \\
& & YS & 61 & 4 & 0.5250 & 0.5750 & 0.4741 & 0.3123 \\
& & HS & 93 & 3 & 0.4312 & 0.5282 & 0.4545 & $0.0021^{*}$ \\
\hline
\end{tabular}

$\mathrm{N}=$ number of individuals; $N_{\mathrm{A}}=$ number of alleles; $H_{\mathrm{O}}=$ observed heterozygosity; $H_{\mathrm{E}}=$ expected heterozygosity; $\mathrm{PIC}=$ polymorphism information content; $\mathrm{P}=$ the $\mathrm{P}$ value for the test of Hardy-Weinberg expectations. One asterisk indicates the locus deviated from Hardy-Weinberg proportions (adjusted P-value $<0.025$ ).

Genetic sex identification revealed that 42 of the 70 individuals from the BS, 42 of 61 from the YS, and 54 of 93 from the HS were female. To compare the P value difference between sexes, the allele distribution and diploid genotypes of both the females and males from 
all of the three samples were tested by the exact $G$ test. As a result, no significant difference was observed between females and males in any of these three samples (Table 5).

$\begin{aligned} & \text { Table 4. } F_{\text {ST }} \text { values (the below diagonal) and significant P values (the upper diagonal) for the pairwise } \\
& \text { comparison of the samples of half-smooth tongue sole using GHRH-SSR2 and PACAP-SSR. }\end{aligned}$
\begin{tabular}{lccc}
\hline Sample & HS & BS & YS \\
\hline HS & 0.1425 & $0.0000^{* *}$ & $0.0000^{* *}$ \\
BS & & -0.0064 & 0.8018 \\
YS & 0.1634 & \\
\hline
\end{tabular}

Significant genetic differentiation was indicated with two asterisks at $\mathrm{P}<0.01$.

Table 5. $\mathrm{P}$ values of differentiation between female and male half-smooth tongue sole based on the distribution of alleles and diploid genotypes.

\begin{tabular}{lccc}
\hline & Sample & GHRH-SSR2 & PACAP-SSR \\
\hline Genic & BS & 0.0674 & 0.1483 \\
& YS & 0.6248 & 0.2856 \\
Genotypic & HS & 0.1642 & 0.8062 \\
& & & 0.1708 \\
& BS & 0.0586 & 0.3502 \\
& YS & 0.6326 & $0.7493+$ \\
\hline
\end{tabular}

\section{DISCUSSION}

\section{Genomic structure of GHRH and PACAP genes}

In general, the GHRH genes of mammalian and amphibian consist of four exons and three introns, with the mature peptides located in the third exon. Authentic GHRH peptides were identified in eight fish species by in silico analysis (Lee et al., 2007). Moreover, the mature GHRH sequences are almost identical and the peptide cleavage sites (R and GKR) are also conserved. The gene encoding PACAP has been cloned in several species including human and mouse. PACAP gene is composed of four exons encoding cryptic peptides, and PRP and PACAP are arranged in tandem. The sequence of signal peptide and PRP are encoded by the first and the third exon, respectively. The fourth exon encodes the remainder of PRP and the PACAP peptide. Similarly, fish PACAP genes consist of four exons and three introns, and the location of PRP and PACAP coding regions are generally consistent with that of mammals, like in salmon (Parker et al., 1997) and zebrafish (D. rerio) (Fradinger and Sherwood, 2000). Similarly, the gene arrangement in half smooth tongue sole GHRH and PACAP genes are consistent with the above-mentioned species, which indicates that the organization of both genes are highly homologous from fish to mammals.

\section{Differential mRNA expression of GHRH and PACAP between females and males}

Mammalian GHRH mRNA is mainly expressed in the brain (Bagnato et al., 1992), and also in peripheral tissues such as the pancreas, intestine, ovary and testis (Arimura and Shioda, 1995; Mayo et al., 1995). Similarly, expression of GHRH gene in tissues of teleosts 
has been reported not only in the hypothalamus, but also in peripheral tissues such as the testis and ovary (Bagnato et al., 1992; Fradinger and Sherwood, 2000). In this study, GHRH of halfsmooth tongue sole was mainly expressed in the brain, and also in the pituitary, spinal cord, gonads, blood and gill, which was consistent with the previous reports.

In mammals, PACAP is a pleiotropic neuropeptide located within a wide range of tissues, including the brain, intestine, lung, adrenal gland, ovary and testis (Arimura, 1998; Wong et al., 2000). In fish, the tissue distribution of PACAP mRNA was examined in catfish (I. punctatus) (McRory et al., 1995), salmon (Parker et al., 1997) and zebrafish (D. rerio) (Fradinger and Sherwood, 2000), and the mRNA expression has been demonstrated throughout the central nervous system and in several peripheral tissues, such the brain, pituitary, spinal cord, gastrointestinal tract, ovary, testis, kidney, liver, heart, gill (Wong et al., 2000) and eye (Fradinger and Sherwood, 2000). However, PACAP of grass carp was found to express in the brain but not other tissues (Sze et al., 2007). In this study, expression distribution of PACAP mRNA was generally consistent with the results from fish to mammals except for the gonads. The absence of PACAP in gonads has also been reported in the previous research on grass carp (Sze et al., 2007) and half smooth tongue sole (Ji et al., 2011).

It was originally hypothesized that GHRH was encoded in the same gene with PACAP, and the endocrine significance of the presence of this phenomenon is that the expression of both genes are controlled by the same regulatory mechanisms, which may result in the same physiological function such as the release of GH. In this study, even though the two genes are encoded by separate genes, they are still localized in some of the same tissues with familiar patterns of expression distribution.

GHRH is the predominant regulator which acts on the pituitary gland stimulating the synthesis and release of GH from somatotrophic cells and influencing the growth in mammals (Mayo et al., 1995). While in fish, initial studies analyzing the potential role of GHRH-like peptide in the control of GH release did not show similar results, either consistent with the previous studies in mammals or failed to demonstrate a major stimulatory action in releasing GH in vitro (Luo and McKeown, 1991; Parker et al., 1997; Rousseau et al., 2001). However, recent identifications showed that authentic GHRH mRNA of goldfish (C. auratus) was detected mostly in the brain, whereas GHRH receptor mRNA was found in both brain and pituitary. The expression patterns of these genes in the brain-pituitary axis further support the functional role of the previously uncharacterized GHRH action in stimulating GH secretion and release from the anterior pituitary (Lee et al., 2007).

PACAP is also involved in a variety of biological functions. It is suggested that PACAP may act as a hypophysiotropic factor regulating pituitary hormone secretion in fish (Wong et al., 2000). Moreover, it also acts as a trophic factor in a number of peripheral tissues, such as operator of gonadal activity in gonads and inducer of gastric smooth muscles (Arimura, 1998). In goldfish (C. auratus), mRNA transcripts of PACAP receptors have been identified in the pituitary as well as in various brain areas. Consistent with the pituitary expression of PACAP receptors, PACAP analogs are effective in stimulating GH secretion both in vivo and in vitro, which support the hypothesis that PACAP is produced in the hypothalamus and delivered to the anterior pituitary to regulate GH release, and may be involved in seasonal regulation of body growth in fish (Wong et al., 2000). In the brain, PACAP has also been shown to stimulate GH release in vitro in salmon and eel (Anguilla anguilla) pituitary cells in a dose dependent manner (Parker et al., 1997).

In mammals, both GHRH and PACAP belong to the same superfamily, which can 
regulate the release of GH. It has been previously reported that GHRH-like peptide stimulates GH secretion in various teleost species, including the sockeye salmon (Oncorhyncus nerka) (Parker et al., 1997) and the rainbow trout (Oncorhynchus mykiss) (Luo et al., 1990). In contrast, the research in the eel (A. anguilla) has shown that, PACAP may participate in the regulation of somatotrope cells, while GHRH has no effect on GH release. In this primitive teleost fish, PACAP rather than GHRH plays a role in the regulation of GH secretion (Montero et al., 1998). Consistent with the above-mentioned conclusion, it has been reported that in salmon, PACAP is far more efficient than native GHRH-like peptide in stimulating GH release (Parker et al., 1997). These observations strongly suggest that PACAP plays a major physiological role in the control of GH secretion in fish.

GHRH and PACAP mRNA levels were observed significantly higher in males compared with females in sexual mature fish at most of the developmental stages in this study. It is well known that GHRH regulates GH mRNA expression. Moreover, it has been reported that an increase in GHRH mRNA expression accompanied GH deficiency, while a decrease in GHRH mRNA accompanied GH excess in mice. Frohman et al. further demonstrated that expression of the GHRH gene is regulated by GH in a classical feedback manner, with hypophysectomy leading to increased GHRH expression that is reversed by GH treatment (Frohman et al., 1989). These findings could explain the significantly higher GHRH and PACAP mRNA levels observed in males compared to females, which may result from GH deficiency.

Initial studies have demonstrated a significantly higher level of GH transcription in the fast growing female eels in comparison to the males (Degani et al., 2003). Similar results were detected in yellow perch (Perca flavescens), which also exhibit an interesting female biased sexual size dimorphism (SSD) wherein females grow faster than males, and explain the growth rate differences between females and males (Lynn, 2006). Consistent with the abovementioned results, GH mRNA levels of the female half smooth tongue sole were significantly higher than that of males during most the developmental stages, even in the sexual mature individuals (Ma Q, Liu SF and Zhuang ZM, unpublished results). As a result, the difference in growth between females and males could be a consequence of sexually dimorphic GH secretion influenced by GHRH and PACAP.

It is of great interest that the extra-large males exhibit the lowest mRNA transcripts of both GHRH and PACAP in the mainly expressed tissues compared with normal females and males. Furthermore, a high level of PACAP mRNA was detected in pituitary of normal male individuals, and negligible expression in that of females and extra-large males. Together with the findings that sexual growth dimorphism caused by higher level of GH in female and extra-large male individuals comparing with normal males (Ma Q, Liu SF and Zhuang ZM, unpublished results)., we suggest that the difference in growth is a consequence of GH secretion influenced by GHRH and PACAP, and PACAP plays an important role in the control of GH secretion comparing with GHRH.

\section{Microsatellite polymorphism in half-smooth tongue sole GHRH and PACAP genes}

In general, hatchery stocks showed a reduced genetic variability mainly due to allele loss, which may result in the reduction of effective population size and compromised adaptability of the population (Allendorf and Phelps, 1980). Based on a comparison of the genetic diversity in four wild samples and one hatchery sample of half-smooth tongue sole (Liu et al., 
2008), the hatchery sample possessed the lowest genetic viability. In this study, the genetic diversity in the HS sample collected from the full-sib family was much lower than that of the wild samples (YS and BS).

Previous studies have demonstrated that polymorphisms in GHRH might be one of the important genetic factors that influence carcass yield in beef cattle (Cheong et al., 2006). Moreover, GHRH polymorphisms were associated with the average daily gain and fat thickness in pigs, which confirmed the potential usefulness of GHRH in marker-assisted selection programs (Franco et al., 2005). Meanwhile, sequence variation in the PACAP gene could affect growth hormone secretion, thus indirectly affecting growth and condition traits, which may explain the strong association of the SNP genotype GHRH/PACAP with early growth (Tao and Boulding, 2003). Recent studies have documented that the level of hormones in the $\mathrm{GH}$ axis can be used as a marker of growth performance in teleost fish. Hence, it is of great interest to determine whether the polymorphic GHRH and PACAP microsatellites are associated with the growth patterns in the sexes.

Moreover, the mini- and microsatellites located in the non-coding region have been suggested to modulate gene expression. Klenova et al. (2004) identified two transcription factors binding to the minisatellite located in the second intron of the serotonin transporter gene. Almuly et al. (2008) reported that the minisatellite of the first intron might play an important role in regulating GH gene expression. Similarly, microsatellite polymorphisms in intron II of the human Toll-like receptor 2 gene were associated with promoter activities and the association is correlated with gene expression (Yim et al., 2006). Further studies on the microsatellites in GHRH and PACAP genes are needed to reveal any possible effects on the growth traits and regulation of gene expression.

To date, there has been no report on sex-linked microsatellites in the fish GHRH and PACAP genes, which was the original reason for analyzing the difference in the microsatellite polymorphisms in the these two genes between sexes. Although the expected results were not obtained, these polymorphic microsatellite markers will nevertheless be useful in analyzing the population genetic structure of half-smooth tongue sole.

\section{ACKNOWLEDGMENTS}

The authors are very grateful to the Zhonghai, Mingbo, and Xinyongfeng Hatchery Stations for their support in fish culture and sampling. We also thank Prof. Quanqi Zhang and Dr. Xubo Wang from the Ocean University of China for their great help in genetic sex identification of samples. Research supported by the National Natural Science Foundation of China (Grant \#30871913 and \#31172411) and the Special Fund of the "Taishan Scholar" Project of Shandong Province.

\section{REFERENCES}

Allendorf FW and Phelps SR (1980). Loss of genetic variation in a hatchery stock of cutthroat trout. Trans. Am. Fish. Soc. 109: 537-543.

Almuly R, Skopal T and Funkenstein B (2008). Regulatory regions in the promoter and first intron of Sparus aurata growth hormone gene: Repression of gene activity by a polymorphic minisatellite. Comp. Biochem. Physiol. Part. D Genomics Proteomics 3: 43-50.

Arimura A (1998). Perspectives on pituitary adenylate cyclase activating polypeptide (PACAP) in the neuroendocrine, 
endocrine, and nervous systems. Jpn. J. Physiol. 48: 301-331.

Arimura A and Shioda S (1995). Pituitary adenylate cyclase activating polypeptide (PACAP) and its receptors: neuroendocrine and endocrine interaction. Front. Neuroendocrinol. 16: 53-88.

Bagnato A, Moretti C, Ohnishi J, Frajese G, et al. (1992). Expression of the growth hormone-releasing hormone gene and its peptide product in the rat ovary. Endocrinology 130: 1097-1102.

Breathnach R and Chambon P (1981). Organization and expression of eucaryotic split genes coding for proteins. Annu. Rev. Biochem. 50: 349-383.

Chen SL, Li J, Deng SP, Tian YS, et al. (2007). Isolation of female-specific AFLP markers and molecular identification of genetic sex in half-smooth tongue sole (Cynoglossus semilaevis). Mar. Biotechnol. 9: 273-280.

Cheong HS, Yoon DH, Kim LH, Park BL, et al. (2006). Growth hormone-releasing hormone (GHRH) polymorphisms associated with carcass traits of meat in Korean cattle. BMC Genetics 7: 35.

Degani G, Tzchori I, Yom-Din S, Goldberg D, et al. (2003). Growth differences and growth hormone expression in male and female European eels [Anguilla anguilla (L.)]. Gen. Comp. Endocrinol. 134: 88-93.

Excoffier L and Lischer HEL (2010). Arlequin suite ver 3.5: a new series of programs to perform population genetics analyses under Linux and Windows. Mol. Ecol. Resour. 10: 564-567.

Fradinger EA and Sherwood NM (2000). Characterization of the gene encoding both growth hormone-releasing hormone (GRF) and pituitary adenylate cyclase-activating polypeptide (PACAP) in the zebrafish. Mol. Cell Endocrinol. 165: 211-219.

Franco MM, Antunes RC, Silva HD and Goulart LR (2005). Association of PIT1, GH and GHRH polymorphisms with performance and carcass traits in Landrace pigs. J. Appl. Genet. 46: 195-200.

Frohman LA, Downs TR, Chomczynski P, Brar A, et al. (1989). Regulation of growth hormone-releasing hormone gene expression and biosynthesis. Yale J. Biol. Med. 62: 427-433.

Gahete MD, Duran-Prado M, Luque RM, Martinez-Fuentes AJ, et al. (2009). Understanding the multifactorial control of growth hormone release by somatotropes: lessons from comparative endocrinology. Ann. N. Y. Acad. Sci. 1163: 137-153.

Goldenberg N and Barkan A (2007). Factors regulating growth hormone secretion in humans. Endocrinol. Metab. Clin. North Am. 36: 37-55.

Ji XS, Chen SL, Jiang YL, Xu TJ, et al. (2011). Growth differences and differential expression analysis of pituitary adenylate cyclase activating polypeptide (PACAP) and growth hormone-releasing hormone (GHRH) between the sexes in half-smooth tongue sole Cynoglossus semilaevis. Gen. Comp. Endocrinol 170: 99-109.

Klenova E, Scott AC, Roberts J, Shamsuddin S, et al. (2004). YB-1 and CTCF differentially regulate the 5-HTT polymorphic intron 2 enhancer which predisposes to a variety of neurological disorders. J. Neurosci. 24: 5966-5973.

Lee LT, Siu FK, Tam JK, Lau IT, et al. (2007). Discovery of growth hormone-releasing hormones and receptors in nonmammalian vertebrates. Proc. Natl. Acad. Sci. U. S. A. 104: 2133-2138.

Liu XZ, Zhuang ZM, Ma AJ, Chen SQ, et al. (2005). Reproductive biology and breeding technology of Cynoglossus semilaevis. Mar. Fish. Res. 26: 7-14.

Liu YG, Yu ZG, Bao BL, Sun XQ, et al. (2008). Population genetics studies of half-smooth tongue sole Cynoglossus semilaevis using ISSR markers. Biochem. Syst. Ecol. 36: 821-827.

Livak KJ and Schmittgen TD (2001). Analysis of relative gene expression data using real-time quantitative PCR and the 2(-Delta Delta C(T)) Method. Methods 25: 402-408.

Lugo JM, Rodriguez A, Helguera Y, Morales R, et al. (2008). Recombinant novel pituitary adenylate cyclase-activating polypeptide from African catfish (Clarias gariepinus) authenticates its biological function as a growth-promoting factor in low vertebrates. J. Endocrinol. 197: 583-597.

Luo D and McKeown BA (1991). Interaction of carp growth hormone-releasing factor and somatostatin on in vitro release of growth hormone in rainbow trout (Oncorhynchus mykiss). Neuroendocrinology 54: 359-364.

Luo DS, McKeown BA, Rivier J and Vale W (1990). In vitro responses of rainbow trout (Oncorhynchus mykiss) somatotrophs to carp growth hormone-releasing factor (GRF) and somatostatin. Gen. Comp. Endocrinol. 80: 288-298.

Lynn S (2006). Cloning and Expression of Key Endocrine Genes in a Study on Estrogen Stimulated Sexual Size Dimorphism (SSD) in Yellow Perch. Thesi. University of Kentucky, Lexington.

Mayo KE, Godfrey PA, Suhr ST, Kulik DJ, et al. (1995). Growth hormone-releasing hormone: synthesis and signaling. Recent Prog. Horm. Res. 50: 35-73.

McRory J and Sherwood NM (1997). Two protochordate genes encode pituitary adenylate cyclase-activating polypeptide and related family members. Endocrinology 138: 2380-2390.

McRory JE, Parker DB, Ngamvongchon S and Sherwood NM (1995). Sequence and expression of cDNA for pituitary adenylate cyclase activating polypeptide (PACAP) and growth hormone-releasing hormone (GHRH)-like peptide in catfish. Mol. Cell Endocrinol. 108: 169-177.

Montero M, Yon L, Rousseau K, Arimura A, et al. (1998). Distribution, characterization, and growth hormone-releasing activity of pituitary adenylate cyclase-activating polypeptide in the European eel, Anguilla anguilla. Endocrinology 
139: 4300-4310.

Parker DB, Power ME, Swanson P, Rivier J, et al. (1997). Exon skipping in the gene encoding pituitary adenylate cyclaseactivating polypeptide in salmon alters the expression of two hormones that stimulate growth hormone release. Endocrinology 138: 414-423.

Rice W (1989). Analyzing tables of statistical tests. Evolution. 43: 223-225.

Rousseau K, Le Belle N, Pichavant K, Marchelidon J, et al. (2001). Pituitary growth hormone secretion in the turbot, a phylogenetically recent teleost, is regulated by a species-specific pattern of neuropeptides. Neuroendocrinology 74: 375-385.

Rousset F (2008). Genepop'007: a complete re-implementation of the genepop software for Windows and Linux. Mol. Ecol. Resour. 8: 103-106.

Sambrook J, Fritsch E and Maniatis T (1989). Molecular Cloning: A Laboratory Manual 1-3. Cold Spring Harbor Laboratory Press, New York.

Sze KH, Zhou H, Yang Y, He M, et al. (2007). Pituitary adenylate cyclase-activating polypeptide (PACAP) as a growth hormone (GH)-releasing factor in grass carp: II. Solution structure of a brain-specific PACAP by nuclear magnetic resonance spectroscopy and functional studies on GH release and gene expression. Endocrinology 148: 5042-5059.

Tao WJ and Boulding EG (2003). Associations between single nucleotide polymorphisms in candidate genes and growth rate in Arctic charr (Salvelinus alpinus L.). Heredity 91: 60-69.

Weir BS and Cockerham CC (1984). Estimating F-statistics for the analysis of population structure. Evolution 38: 1358-1370.

Wong AO, Li WS, Lee EK, Leung MY, et al. (2000). Pituitary adenylate cyclase activating polypeptide as a novel hypophysiotropic factor in fish. Biochem. Cell Biol. 78: 329-343.

Yim JJ, Lee HW, Lee HS, Kim YW, et al. (2006). The association between microsatellite polymorphisms in intron II of the human Toll-like receptor 2 gene and tuberculosis among Koreans. Genes Immun. 7: 150-155. 